\title{
Memoria histórica y efecto fantástico en la narrativa breve de Jesús Moncada
}

\section{Historical memory and fantastic effect in Jesús Moncada's short stories}

\author{
Alfons Gregori \\ Uniwersytet im. Adama Mickiewicza w Poznaniu, Instytut Filologii Romańskiej \\ Pracownia Katalonistyki \\ alfons@amu.edu.pl
}

\begin{abstract}
The main aim of this article is to analyse the complexity of the subject of memory in the work of Jesus Moncada, as an author from Aragon writing in Catalan and introducing the Spanish Civil War issue in fantastic fiction, namely in Històries de la mà esquerra [Stories of the Left Hand] (1981). Furthermore, the short story that closes the book, "D'uns vells papers de música" [Old Sheet Music], is discussed to illustrate that matter in the context of the conflict between the real and the fantastic, on the one hand, and between history and memory, on the other hand. Thus, in the mentioned narrative fiction collective memory stands as a specter whose condition is noticed by its anachronistic return under grotesque forms, resulting from the horror facing death or the unreal, and from the irony interwoven by the narrator. In doing so Moncada problematizes any attempt to reconstruct historical memory based on literature.
\end{abstract}

Keywords: Contemporary Catalan literature, fantastic short stories, Jesús Moncada, historical memory, collective memory

A principios de los años 80 hacía su aparición en la escena literaria barcelonesa en lengua catalana Jesús Moncada (1941-2005). La inclusión de elementos fantásticos en su primera colección de cuentos, Històries de la mà esquerra i altres narracions (1981), supuso un interesante y arriesgado punto de partida en el panorama literario catalán dominado por el realismo, ubicándose pues en la periferia respecto a la corriente preponderante. Moncada representaba la entrada de una 
determinada influencia de la posmodernidad que seguramente muchos no supieron leer como tal, aunque, como bien define Martínez-Gil (2006, p. 307), fueron los 80 el período de establecimiento de dicha dominante cultural. Así, algunos relatos de Històries de la mà esquerra, entre ellos "D'uns vells papers de música", analizado en la parte final del artículo, encajan en el concepto de literatura fantástica que se define por la irrupción de un fenómeno o hecho irreal en una representación verosímil de nuestro mundo, creando un efecto fantástico de inquietud, miedo, terror, y pudiendo provocar dudas ontológicas o existenciales en los lectores. ${ }^{1}$ Una de las características más destacadas de lo fantástico de Moncada es el calculado y sugerente empleo de lo grotesco, afinando la ironía o explorando el sarcasmo y la irreverencia hacia la ultratumba en combinación con el espanto ante lo fantasmagórico o macabras alusiones a la muerte. De este modo, el elemento grotesco estaría relacionado con la tradición estética del barroco, ${ }^{2}$ resonando en el título de la narración breve mencionada la voz de Salvador Espriu, el autor que más destacó en la introducción e implantación de dicha estética en las letras catalanas contemporáneas.

La mayoría de estudios acerca de la producción literaria de Moncada han girado sobre un motivo fundamental: la nostalgia de su Mequinenza natal, el "Poble vell" recreado en los tiempos previos a su desaparición casi total bajo las aguas durante el tardofranquismo, por orden de las autoridades del régimen en su afán de construir pantanos y embalses, surgiendo entonces una nueva villa homónima que continúa en pie en la comarca del Bajo Cinca. Cierto es que en muchos de sus relatos - escenificados en los años del franquismo - abundan las referencias a los tiempos de la II República, ${ }^{3}$ y que podría parecer que la nostalgia o la melancolía es el sentimiento dominante. Sin embargo, esto ya fue matizado por Cònsul (1995) y rebatido argumentadamente por estudiosos como Martínez-Gil (2006) o Gregori Soldevila (2006). En el presente artículo pretendo llevar a cabo una aproximación al tema de la memoria histórica en los relatos de Històries de la mà esquerra desde una óptica que replantea el asunto, asumiendo la acertada exigencia de Alonso (1997, p. 79) de tratar autónomamente los relatos de Moncada respecto a su novelística. Así, se trata de replantear el asunto de la memoria colectiva — vinculado las más de las veces de forma unívoca a una estética determinada - analizando el modo en que el uso de lo irreal y de recursos grotescos condiciona la imagen final de la recreación de un mundo "perdido" marcado por el conflicto ideológico.

\footnotetext{
${ }^{1}$ Para un análisis completo y detallado de las teorías de lo fantástico y de las modalidades o géneros colindantes, véase Gregori (2015, pp. 21-84).

${ }^{2}$ Cònsul vinculó la concepción de la muerte presente en sus relatos con una corriente clave de la literatura española, o sea un barroco de cariz pesimista absorto en la brevedad de la existencia que estaría representado, de acuerdo con el crítico, por Quevedo o Gracián, y llegaría hasta Gómez de la Serna (2005, p. 45)

${ }^{3}$ Para un estudio sobre lo fantástico y las referencias a la ideología y las políticas republicanas en la narrativa breve de Moncada, véase Gregori (2016).
} 


\section{LA CONSTRUCCIÓN DE UNA MEMORIA DE MEQUINENZA}

La conjunción de haber devenido un escritor leído en muchos rincones de los territorios catalanohablantes, incluso traducido a bastantes más lenguas que otros reconocidos autores contemporáneos, $\mathrm{y}$ de haber formado parte de una comunidad alejada de los focos de atención hizo de Moncada "la voz autorizada" de un espacio ignoto, apartado, desdeñado. Entre aquellos lectores que descubrían todo un mundo a través de los relatos del escritor, el hecho de que este escribiera sobre aquello que él parecía conocer de primera mano daba la impresión de ser la opción más natural. Cabe mencionar la caracterización de la figura del testigo en palabras de Traverso (2006, p. 18), quien, en alusión al estudio de Wieviorka L’Ére du témoin (1998), lo esquematiza como aquella voz situada en un pedestal predeterminado, encarnando un pasado cuyo recuerdo se prescribe como deber cívico y asumiendo además la posición corriente entre este tipo de testimonios como víctima. Moncada se convertía nolens volens en uno de ellos, uno de esos testigos de excepción, en este caso del final fatídico de un mundo hundido bajo las aguas. El contenido físico de la antigua Mequinenza ciertamente había sido finiquitado por culpa de una de las múltiples decisiones del régimen franquista, habitualmente arbitrario y despiadado ante los débiles y los grupos minorizados como los hablantes del catalán. Nació entonces el denominado "mite de Mequinensa", que la crítica llegó a equiparar con otros ya más fijados en el canon catalán o incluso en las letras internacionales, como el de Bearn de Llorenç Villalonga (Cònsul, 1995, p. 140) o el de Macondo de García Márquez. Así, como todo mito que se valga, disponía de mecanismos de despliegue analógico hacia un simbolismo diverso: desde la identificación implícita entre esa agitada proyección de Mequinenza con un espíritu republicano que había sido reprimido por la fuerza bruta del franquismo, o la visión literaria de esa localidad como un microcosmos de una Cataluña en que confluían lo urbano y lo rural, igualmente víctima del obscurantismo gris bajo el régimen de Franco, o simplemente el trasunto narrativo de esa lengua, de tradiciones y costumbres de antaño que el mundo moderno había condenado al confinamiento y, en último término, a la desaparición. Es decir, como se observa, Mequinenza tanto podía leerse como la representación de una realidad ideológica (un conflicto ideológico irresoluble), de una realidad nacional o de una realidad social y cultural del pasado.

Sin duda, fue esta última opción aquella que capitalizó la mayor parte de los estudios críticos acerca de la obra de Moncada. Lo demuestran la gran cantidad de trabajos sobre el léxico y los recursos fraseológicos empleados en sus relatos y la atracción de bastantes críticos por la nostalgia del mito de Mequinenza. Como sintetiza muy acertadamente Gregori Soldevila: "Segons el discurs crític majoritari, l'obra de Moncada s'ha d'entendre com la fixació literària de la memòria col·lectiva, com la crònica destinada a salvaguardar el patrimoni dels records mequinensans, a pesar de les reserves de l'autor, sempre amatent" (2006, pp. 134-135). E igual que 
podía intentar salvaguardar el patrimonio de esa memoria de costumbres, tradiciones y situaciones particulares de la localidad en cuestión, podría representar también la fijación de unas memorias colectivas paralelas: la memoria de unas ideologías de la resistencia ante al poder dictatorial, o la de una nación a la cual las armas impidieron el pleno desarrollo democrático. ${ }^{4}$ Sin embargo, la misma Gregori Soldevila pone sobre la mesa la incongruencia de dicha concepción respecto al discurso literario inscrito en la narrativa de Moncada, poniendo ejemplos específicos de su novelística. De este modo, en Camí de sirga "la crònica fixa com a memòria col·lectiva la ficció que millor s'ajusta a la percepció que els protagonistes tenen, a posteriori, dels esdeveniments viscuts" (2006, p. 135), y a su vez Estremida memòria "insisteix a «desprestigiar» la credibilitat de la memòria popular com a font d'informació" (2006, p. 136). En síntesis, como señala la investigadora valenciana: "l'exercici de memòria que ens proposa Moncada consisteix més a plantejar una interrogació sobre els mecanismes de captació del real i sobre la relació de la ficció amb la realitat que en resurreccions de paradisos negats sota les aigües" (2006, p. 138).

En este sentido, y empleando la terminología de Benjamin, el discurso literario autorial de Moncada se dedicó a reformular críticamente la experiencia transmitida (Erfahrung) - propia de las sociedades tradicionales-, a lo cual le habría conducido su experiencia vivida (Erlebnis), al vivir y formarse como intelectual en una modernidad que tiende a focalizar el interés en dicha experiencia - a diferencia del Erfahrung: la formación en un ambiente influenciado por autores como Calders, su labor de traductor y las múltiples lecturas que dejaban atrás la construcción del relato según el modelo psicológico de vertiente realista. De hecho, en el debate que se produjo acerca del estatus de literatura rural o urbana que podían tener las obras de Moncada, y lo que ello implicaba en relación con la modernidad de las mismas, cabría tener en cuenta la reproducción de un tipo de "experimentación de lo vivido" propia de hábitos sociales anteriores al desarrollo de la modernidad y la posmodernidad. La antigua Mequinenza fue en su momento un lugar de coexistencia de lo urbano y lo rural, del proletariado del capitalismo industrial y del campesinado escasamente transformado, coexistencia que se proyecta de modo diverso en Històries de la mà esquerra y otros libros de Moncada. Con todo, si en la mayoría de los relatos domina un Erfahrung que contribuye decisivamente al planteamiento irónico y metaficcional destacado brillantemente por Gregori Soldevila, ante muchos lectores también ofrece paradójicamente la imagen de una narrativa preocupada esencialmente por la memoria. Se trata de esa memoria que se desarrolla por el impulso del Erfahrung en grupos reducidos que conforman comunidades autosuficientes -al menos ficcionalmente_-, como sugiere Crameri:

\footnotetext{
${ }^{4}$ Cito la definición de este concepto recogida por Nora y traducida por Cuesta (2008, p. 68): "La memoria colectiva es el recuerdo, o el conjunto de recuerdos, conscientes o no, de una experiencia vivida y/o mitificada por una colectividad, alimentada por una identidad de la que el sentimiento del pasado es parte integrante".
} 
Moncada seems especially interested in the way that the people of close-knit communities construct stories - or even myths - of themselves as a collective, using tools such as rumour, gossip, unfounded assumptions, autobiographical memory, selective amnesia, and the consensual creation of versions of events which may or may not be strictly accurate in their detail. (2003, p. 353)

En cualquier caso, no deberíamos tampoco cerrar las vías de comunicación académica con un cierto tipo de lecturas que abogan por poner en valor la memoria en los relatos de Moncada, aunque su grado de veracidad haya sufrido una tergiversación ideológica: solo cabe recordar que la publicación de Històries de la mà esquerra se produjo pocos años después del inicio de la Transición, saliendo de una dictadura que monopolizaba el conocimiento histórico y castraba cualquier memoria de la II República, la Guerra Civil o los vencidos de la posguerra que fuera más allá del guion absolutamente maniqueo establecido. Se trataba, además, de una época en que obras como Pedra de tartera (1985), de Maria Barbal, reivindicadoras de una memoria colectiva de los desfavorecidos desde la óptica de los testimonios, resultaban más bien escasas en el panorama literario catalán coetáneo. Moncada, en varias ocasiones, rehuyó la calificación de cronista de una memoria nostálgica, en efecto, pero el hecho de escribir sobre unos periodos, unas actitudes ideológicas y una ciudad hundida por orden del franquismo, así como el hecho de publicar sus primeros relatos en un momento en que imperaba reestructurar una memoria histórica ${ }^{5}$ cada vez más institucionalizada — como mínimo en territorio catalán - provocaba la emergencia de lecturas enfocadas hacia dicha memoria. ${ }^{6}$ Esto no significa que hubiera una intención autorial de presentarse como autor comprometido a través de la literatura en cuestiones políticas concretas. ${ }^{7}$

¿Y de dónde surgía ese lado imposible de los mismos primeros relatos de Moncada? Cònsul sospechaba que las historias fantásticas del escritor venían "dictades per la singularitat d'una geografia de misteris" (1995, p. 132), es decir, que el hecho de tener lugar en ese espacio periférico subrayado anteriormente determinaba el

\footnotetext{
${ }^{5}$ En referencia a este discutido concepto, cabe referir la definición aportada por Lavabre: "Llamaremos memoria histórica a los usos del pasado y de la historia tal y como grupos sociales, partidos, iglesias, naciones o Estados se lo apropian. Apropiaciones dominantes o dominadas, apropiaciones plurales y selectivas en todo caso, marcadas por el sello del anacronismo, de la semejanza entre el pasado y el presente [...]" (Cuesta, 2008, p. 445).

${ }^{6}$ Crameri no duda en vincular a nivel intradiegético este interés por la memoria colectiva con la comunidad configurada en el relato, siendo el mito autocreado de Mequinenza el punto de partida de una historia colectiva que ayuda a dicha comunidad a sobrevivir y prosperar (2011, p. 18).

${ }^{7}$ Así, en una entrevista el escritor afirma, aludiendo a Camí de sirga y refiriéndose a sí mismo en tercera persona: "Jesús Moncada, com a persona, sempre ha estat de la banda dels febles, que sempre són els que reben. [...] Exemple d'aquests dominats són la majoria dels personatges que apareixen a l'obra. Aquest, però, és només un aspecte de la novel·la, que no voldria que s'interpretés com una novel·la social. No m'agraden les etiquetes, jo sóc un contador d'històries” (Alonso, 1997, p. 75).
} 
alejarse de un estilo estrictamente mimético. De este modo, la deducción del crítico seguía de alguna manera las premisas de lo maravilloso exótico y lo gótico, géneros en los que la lejanía y la condición periférica daban pie, respectivamente, al elemento irreal. Por lo tanto, volvemos al problema de la transfiguración literaria de esa antigua Mequinenza, en este caso fuente de posibles dudas ontológicas acerca de la realidad representada, por constituir un coto pretendidamente aislado de lo conocido. Su ubicación no impediría, sin embargo, levantar susceptibilidades sobre la verosimilitud del relato ante la mayoría de lectores cuando se presentan fenómenos o hechos fantásticos. La contradicción se produce cuando el mismo Cònsul otorga condición de autenticidad al contenido narrado en los primeros cuentos y en la novela Camí de sirga, al tratar el particular carácter elegíaco de esta:

I l'elegia és paradoxal perquè, com ja succeïa amb els contes, l'autor no s'entreté a teixir lamentacions inútils i ha optat per recuperar, en les pàgines d'una magnífica novel·la, la sensualitat i les ganes de gresca que senyorejaven una Mequinensa liberal i un punt descreguda, atapeïda amb els tropells dels minaires i les històries dels llaüters amunt i avall de l'Ebre. (1995, p. 134)

Fijémonos que en esta cita se indica que es la función autorial $-\mathrm{y}$ no la instancia del narrador- aquella que busca la "recuperación" de una determinada imagen de la población aragonesa, una imagen ligada estrechamente a la historia sociopolítica de la región. Justamente es ese el problema: la memoria vista como un ejercicio de recuperación de algo que existió y que, como tal, es trasladable en el tiempo (y eventualmente el espacio) por medio de un discurso mental convertido en manifestación lingüística. Cuando en un fragmento citado más arriba Crameri se refería al trabajo sobre la memoria en la narrativa de Moncada, focalizaba su atención en la construcción de historias, no en la reconstrucción de las mismas. De este modo, enlazaba con la argumentación de Gregori Soldevila al respecto, convergiendo en que el interés por la manipulación y la reformulación de algo tan etéreo como la realidad sea en forma de costumbres, situaciones, personajes o pensamientos. De hecho, más que tratarse de un debate sobre la importancia o no de la memoria en los textos de Moncada, al ser innegable su relevancia, nos encontramos ante dos formas de entender el concepto de memoria: una notablemente caduca y naíf, que desde un posicionamiento cercano al realismo filosófico identifica lo pensado con una realidad exterior; y otra más escéptica y convincente que, atendiendo a planteamientos constructivistas y al discurso (pos)moderno, niega que tal identificación sea plausible como base de análisis del pensamiento humano y de sus representaciones literarias o artísticas.

Por otro lado, la imagen citada de una población liberal y algo descreída, repleta de mineros, imagen ligada a una parte de la historia sociopolítica de las tierras catalanohablantes, conmina a preguntarnos sobre el papel de la historia en la obra de Moncada. Críticos como Parcerisas subrayan la atención prestada por el autor a la 
historia moderna en sus seis obras de creación publicadas (2005, p. 38), retomando su consideración sobre el papel concreto de lo histórico en la primera de ellas, que no es otro que el de aportar verosimilitud a partir de detalles concretos extraídos del mundo real, pero hilvanando el relato como un mundo mítico propio (2005, p. 38). En este sentido, hay un problema ideológico irresuelto: el título del volumen de cuentos aquí analizado menciona la palabra "izquierda", intensamente connotada en lo político. Se trata de uno de los ejes, no solo interpretativos, sino sobre todo nucleares, explicativos de la aparición en escena de las vivencias y experiencias de los personajes que se desarrollan a lo largo de las tramas. Por este motivo, el intento que pretende llevar a cabo Alonso de convertir en "marginal" la vinculación entre la palabra "izquierda" y el contenido de los relatos, o bien afirmar que se trata solo de un cierto ambiente general de cosmovisión progresista (1997, p. 75), constituye una aseveración controvertida y escasamente asumible. ${ }^{8}$ A mi parecer, la "mano izquierda" del título tendría más que ver con la explicitación de un orientación ideológica definida en los relatos — igual que es explicitada en el título-, ya sea como función autorial globalizadora, ya sea como configuración de la voz narrativa, sin que se deje de atraer y captar al mismo tiempo la atención de lectores de gran diversidad ideológica gracias al magistral uso de la ironía y otros mecanismos que evitan el maniqueísmo político en que podría caerse.

\section{2. "D’UNS VELLS PAPERS DE MÚSICA": HISTORIA, MEMORIA Y FANTASTICIDAD}

En esta narración, que cierra el volumen Històries de la mà esquerra, encontramos una trama fantástica con elementos diversos de carácter histórico, político y cultural, conformando el interesante punto final de un conjunto de relatos que tantean en diversas ocasiones la fusión de lo irreal y lo ideológico. La voz narrativa relata un escalofriante episodio, altamente revelador para el protagonista, Jordi Ventura, un minero ya entrado en años. Así, en su regreso a casa en carro, escucha voces aterradoras que le interpelan y, en un momento dado, con una rapidez inusual, se encuentra frente al café de Bartomeu, donde se reunía con sus amigos tras la

\footnotetext{
${ }^{8} \mathrm{Si}$ bien la explicación del título que propone Alonso en referencia a la manera de narrar indirecta, utilizando efectos mediante procedimientos narrativos disimulados, podría ser aceptable como complementaria a la mencionada más arriba, convertirla en la dominante no parece una opción satisfactoria ante la explosión ideológica que se plantea en un buen número de relatos. Es más: las diversas técnicas metaficcionales que estudia Gregori Soldevila y que se aplican abundantemente en la narrativa breve de Moncada no responderían siempre a la intención de narrar "con mano izquierda" para rechazar la exposición directa de los hechos y de las conclusiones que de ello se puedan extraer, como reclama Alonso (1997, p. 75), sino que a menudo ponen justamente bajo el foco de atención esas habilidades narrativas para convertirlas en el centro de la escritura.
} 
jornada de trabajo. El texto contiene las características fundamentales del relato fantástico clásico: el personaje principal es presentado como un acérrimo racionalista pragmático que se burla de las supersticiones; los hechos suceden al atardecer y cuando no hay más testigos, en condiciones tétricas e inquietantes; el protagonista recibe fuertes impresiones con resultados psicosomáticos, sin explicación plausible; $\mathrm{y}$, last but not least, se produce el efecto de lo unheimliche freudiano cuando Jordi reconoce una nota familiar en la voz fantasmagórica. Así, respecto a estos dos últimos aspectos, el personaje primero siente frío, después se altera un poco, pero es cuando reconoce las voces que lo siniestro toma las riendas del sujeto, ya que sus emisores habían fallecido años atrás. El choque con la muerte produce verdadero pavor en el protagonista, que se imagina una escena completa de envejecimiento acelerado, viéndose a sí mismo y a su caballo sufriendo los irreparables golpes del tiempo:

I ell, Jordi, damunt del carro, clavat com un espantall, sense poder baixar ni cridar ni moure's, immòbil per sempre més, se sentiria créixer per les galtes xuclades llargues barbes de cendra; a poc a poc el vent li deixaria terra al damunt, i la terra aniria atapeint-se al solc de les arrugues de la pell, amagaria les velles espardenyes, es ficaria a la butxaca de la fosca camisa i encallaria, a la fi, la corda del rellotge. (Moncada, 2001, p. 116)

Se reproduce de nuevo el efecto fantástico en su vertiente ominosa más auténtica, es decir, mediante un desdoblamiento, en este caso del propio yo en pleno desmoronamiento. No es el único que tiene lugar a lo largo de la narración, como veremos. ${ }^{9}$ Sin embargo, una vez Jordi entra en el local, el cambio de escenario es casi total, puesto que dentro reinan la alegría y el comentario jocoso, ${ }^{10}$ pero no así para él, ya que, a través del narrador, expone varios indicios de la ruina y la desintegración de la vida en ese aparente espacio de ilusión. En cualquier caso, se trata de "un mundo de recuerdos" (Moncada, 2001, p. 117), como advierte el narrador, quien, al ser más joven que los personajes del café, parece ofrecer un punto de vista desde el futuro. Ello le permite determinadas prolepsis que contribuyen a crear una

${ }^{9}$ Aquí cabe comentar la idea de presagio inscrita en la cita y su interpretación por parte de Nemes. Al utilizar el verbo "adonar-se" para referir la sensación de premonición en Jordi ante la percepción de las extrañas voces, la crítica húngara asume que se trata de un presagio con efectos cercanos en el tiempo: "[Jordi] a poc a poc s'adona que la veu és un senyal, que s'ha acabat el seu temps aquí a baix" (2013, p. 154). A mi entender, sin embargo, estamos ante la manifestación de un pronóstico inevitable, aunque sin que de ello resulte la muerte en breve, es decir, una forma de advertir sobre un aspecto que la misma Nemes subraya en su sintético análisis del relato: el eterno retorno. De esta manera, se aunarían antinómicamente el sentido nietzscheano del mismo - por su carga anticlerical y filosófica - y su correspondencia con la temporalidad cíclica de la existencia, es decir, la revuelta de la modernidad frente al conservadurismo arcaico.

${ }^{10}$ Como explicita Ribes, los cafés del municipio eran un espacio privilegiado para la transmisión de la memoria colectiva y de expresión de la ideología política (2011, p. 64). 
atmósfera de decadencia y cercanía del duelo de muerte. En este sentido, Jordi, aunque haya entrado en el café animado por sus parroquianos, está sumido en la tristeza y siente una enorme soledad. De este modo, se puede interpretar que la ominosidad no era una propiedad del exterior - del camino recorrido durante un anochecer perturbador o de las voces que en él se oían-, sino que se halla incrustada en Jordi mismo, convirtiéndose este en una consciencia que percibe lo imposible y vive rodeada de hechos irreales, ligados a un siniestro paso del tiempo. Dentro del bar empieza a tener la impresión de que todo a su alrededor pierde entereza y sus rasgos distintivos: "Eren en un món del qual ell ja no en formava part" (Moncada, 2001, p. 117).

Por consiguiente, nos situamos en una elaboración narrativa en que pasamos subrepticiamente de lo fantástico clásico a un discurso que Alazraki bautizó como neofantástico — si bien un buen número de investigadores lo denominan "fantástico moderno" o "contemporáneo"- - Se trata del modelo en que lo siniestro ya no es una alteración imposible de las leyes y la lógica que conocemos, una transgresión de nuestra normalidad, sino que es la normalidad aquello que se torna insoportablemente ominoso, aquello que convierte el yo en un ser aislado e incomprendido ante una sociedad incomprensible. Si en el gótico, que inicia la literatura fantástica a finales del siglo XVIII, el confinamiento en un espacio tenebroso es el motivo principal del género, en lo neofantástico es el confinamiento en uno mismo. Todo ello se debe a que lo irreal ya no provoca una sorpresa terrorífica en esos personajes que conforman el fondo de la narración, y en este sentido son determinados personajes o los lectores quienes reaccionan con inquietud y aprensión ante la falta de espanto. La transformación de Kafka o bastantes cuentos de Cortázar ejemplifican este nuevo discurso de lo fantástico. Así, en "D’uns vells papers de música" aparece un componente muy recurrido en lo fantástico contemporáneo, es decir, la comicidad, ya que se observan rastros de ironía que acercan el relato a lo grotesco en varias ocasiones, como el apellido mismo del personaje principal, "Ventura", que, siendo verosímil como nombre antroponímico habitual en catalán, significa justamente aquello que constituye el motor de la trama, o sea, lo mismo que en español en su acepción de "suerte": aquello que puede acontecer en el futuro de cada cual, lo imprevisible de la vida.

Con todo, no se trata de una conversión total del discurso, puesto que Jordi, incluso dentro del café, sigue escuchando las voces y estas siguen estremeciéndolo, hasta casi el final de la narración. Sea como sea, durante su estancia en el local la ominosidad arraiga en su propio cuerpo, transformándolo o modificando su percepción de él en base a un paso del tiempo incontrolado: sus manos padecen una regresión y vuelven a ser las manos de la infancia, edad que reconoce básicamente por el efecto de las sensaciones táctiles de sus primeros años. A partir del motivo de las manos el narrador recorre gradualmente las edades de Jordi. Obviamente, no se trata de una opción neutra: las manos simbolizan la clase trabajadora, sea obrera, campesina o menestral, aquellas que se alzaron masivamente en Mequinenza y muchos otros sitios para combatir a las tropas rebeldes de Franco. 
Como vemos, el componente histórico está muy presente en la narración. La primera mención del mismo se introduce en el espacio del café a través de un simbólico calendario de antes de la guerra, carente de hojas. Ahora bien, se trata de una entrada de lo histórico que conduce al absurdo, ya que, como afirma el narrador, los cruces temporales de cariz fantástico invalidan cualquier razonamiento: "Aquella nit el temps ja no tenia sentit, como no en tenia el calendari esfullat" (Moncada, 2001, p. 121). De este modo, el aspecto que inaugura la dimensión histórica de un relato que en su primera parte parecía un texto fantástico tradicional se refiere al episodio traumático de la lucha fratricida. Y este será el núcleo temático de su recuerdo: todo gira entre el antes y el después de la guerra, a partir de la experiencia individual del protagonista. Ese espacio temporal previo es representado simbólicamente por una cupletista, Paca la Xina, que además se acompaña del tópico del ubi sunt: "Paca! ¿On ets, Paca la Xina?” (Moncada, 2001, p. 116). La artista es rememorada en los años de juventud de Jordi, cuando el régimen de tolerancia de la República permitía que las mujeres cantaran semidesnudas en locales frecuentados por las clases populares. Se representa la idea, pues, de un tiempo anterior a la guerra - y por ello republicano - como un período de celebración, de ilusión y de espectáculo, en paralelo con la visión de la soledad como de un final de fiesta, que se manifiesta cuando Jordi identifica dicha sensación con el final de la fiesta mayor de su adolescencia. Celebración y República, por un lado, y soledad y posguerra, por el otro, configuran binomios contrapuestos que sintetizan la función de la historia cuando esta se imbrica con la memoria colectiva e individual del protagonista. Incluso el título mismo del relato remite a ese "fin de fiesta", puesto que se refiere al hecho de que durante la Guerra Civil unas ratas devoraron las partituras de uno de los personajes, Manolet, músico a la vez que panadero.

Jordi aparece como una representación simbólica de un siglo desesperanzado: por las fechas deducimos que podría haber nacido en 1914, con la Primera Guerra Mundial, y hacia los veintidós años habría tenido que empuñar las armas, o sea, en 1936. La guerra va a constituir a partir de ese momento del relato el eje central del dolor por el paso del tiempo, de lo ominoso: a través de símbolos, como el galón rojo de un compañero que ejercía de comisario de batallón, o de menciones directas a episodios del conflicto, como la ofensiva de Singra, que resultó un fracaso para las tropas republicanas en el marco de la Batalla de Teruel. En este contexto, Jordi revive el dolor sufrido entonces - concretamente mientras fue prisionero del bando franquista - haciendo dudar al lector sobre su origen: la memoria y su poder psicosomático, o bien una conexión de orden fantástico entre el pasado y el presente. El final de la guerra no significa una liberación, ya que Jordi es recluido en un campo de concentración - del cual saldrá en marzo 1940, como indica con precisión la voz narrativa-, y su mundo está hundido: la infraestructura de cierto bienestar y aliento que significó la República había desaparecido, sustituida por un viejo café en que solo cantaban canciones machaconas grupos reducidos de paisanos sin intención artística alguna. La tristeza, la soledad, la desazón del protagonista se producen 
durante la larga posguerra, es decir - aunque ello no se explicite en el relato en ningún momento-, durante la dictadura franquista. ${ }^{11}$

La reiteración de las canciones coreadas en el café, además de ser una representación mimética de la desesperación por escapar del aburrimiento "oficializado", simboliza el bucle de la memoria en el cual Jordi había caído y que lo convertía en un esclavo de la rememoración para continuar viviendo. En este sentido, ejerce un papel clave la figura del loro del local. Así, un animal conocido por repetir continuamente sonidos que no tienen sentido alguno, asume la función de símbolo del paso a la decadencia, a la vez que de intérprete de un dolor existencial inscrito en el protagonista. De ello solo se salía convirtiendo la monotonía de la cotidianidad en una acción que pareciera mínimamente razonable para empezar a vivir diferente. $\mathrm{Y}$ eso es de lo que parece tomar consciencia el protagonista:

L'oncle Jordi va sentir la necessitat d'aturar aquella veu, de tallar-la i tornar a ser ell; el que aquella tarda, assegut dalt del carro, somiava amb els amics i el rom, amb la tendra alegria de viure, un home amb esperança. Va comprendre, però, que no ho aconseguiria si es quedava allí dins, al vell cafè del passat [...]. (Moncada, 2001, p. 122)

No obstante, al salir del local algo acongojado, es testigo del segundo desdoblamiento del relato, que consolida la presencia de lo fantástico tradicional en la narración, o cierra el círculo, si se prefiere. En este caso, se trata del carro, que adquiere un doble idéntico, al tiempo que el protagonista se da cuenta de que forzosamente debía subir a uno de los dos:

Endevinava que un dels carros el portaria a un poble de fums i boires, habitat per gent sense nom i sense ombra, on els rellotges no tenien manetes; l'altre el duria de nou a l'esperança, a la vida, a ell mateix. Però també sabia que era inútil intentar esbrinar en quin dels dos era la trampa. (Moncada, 2001, p. 123)

Este relato, que en su desarrollo parecía acercarse a lo fantástico puro de acuerdo con los criterios de Todorov, concluye con un fenómeno fantástico de tintes próximos a la alegoría, reforzando así el simbolismo ideológico del conjunto (el motivo de las manos, por ejemplo). Ahora bien, en realidad los lectores nos quedamos con la duda sobre qué carro escogió Jordi y a qué destino llegó el vehículo, manteniéndose pues una incertidumbre ciertamente todoroviana.

\section{CONCLUSIONES}

La Transición abrió unas puertas que algunos, como Moncada, intentaron cruzar a pesar del pacto de silencio reinante en el Estado español sobre la Guerra Civil.

\footnotetext{
${ }^{11}$ Para un análisis de la vertiente satírica de la obra de Moncada en relación con el franquismo, véase Ribes (2004).
} 
En las páginas precedentes he presentado la complejidad del motivo de la memoria en la obra de Moncada, así como sus derivaciones críticas, y he analizado un relato de Històries de la mà esquerra para ejemplificar la cuestión en el marco de los conflictos implícitos entre lo real y lo fantástico, por un lado, y entre la historia y la memoria, por el otro. En este sentido, a través de la idea motriz de una de las vertientes ominosas del relato, es decir, la huida de una absurda monotonía para dar sentido a la existencia, esta narración enlaza con aquella que abre el volumen, "Jocs de caps", cuyo escenario principal es igualmente un café, y - avanzando por meandros de lo fantástico clásico - finaliza con la toma de consciencia sobre el valor del tiempo y del compromiso ideológico, al no rendirse el protagonista ante esa durísima realidad de posguerra. Si en ese relato inicial la transformación mental se realizaba con un gesto simbólico — volver a poner en marcha un reloj- gracias al impulso ejercido por la visión fantástica sobre el protagonista del relato - el cafetero Hermes_- en este caso el personaje principal, Jordi, se veía impelido a abandonar su espacio de opresión existencial, aunque en oposición directa al fenómeno fantástico, o sea, las voces. Paralelamente, en ambas narraciones la herramienta para intentar cambiar el destino de los protagonistas es un objeto simbólico vinculado con el movimiento, el progreso: un reloj, símbolo del avance en el tiempo, y un carro, representando el desplazamiento espacial. Da la impresión, pues, de que Moncada construye sus relatos a partir de oposiciones simbólicas y que los fundamenta en la importancia del marco espacio-temporal $-\mathrm{y}$ de todo lo que este comporta: Mequinenza y la historia de un pueblo (en el doble sentido de la palabra), el espacio compartido y la memoria, siempre entrelazados en sinuosas imbricaciones-. Ahora bien, en "D’uns vells papers de música" la memoria colectiva, esta vez en su formato representativo de memoria individual sobre hechos, aspectos y figuras del pasado, se alza como un fantasma. La condición espectral de dicha memoria se advierte en el retorno anacrónico de formas grotescas que conllevan tanto el horror ante lo irreal y la muerte, como la ironía entretejida por el narrador. Moncada problematiza, así, cualquier intento de reconstrucción de una memoria histórica a partir de la literatura.

Martínez-Gil, con su lucidez habitual, distinguía dos modelos de escritores catalanes de la posmodernidad, siendo el primero aquel que osaba "poner bigotes a la Gioconda", es decir, los creadores de una nueva literatura que situaba la cultura propia en los parámetros sociales y comerciales del momento, definiendo así un compromiso con los valores del escepticismo, entendidos como medida higiénica social y nacional, así como una manera de mantener la propia comunidad, pero negándole trascendencia; por otro lado, el segundo modelo estaría representado por aquellos escritores que mantuvieron un compromiso con causas lingüísticas e históricas, o con grupos concretos de su comunidad, en un sentido afirmativo más tradicional (2006, p. 310). Seguramente Moncada quiso situarse, con su obra, entre los primeros, sumándose a una soterrada revuelta ante unas formas y una actitud acartonadas que ya no convencían demasiado a muchos intelectuales. Sin embargo, 
numerosos lectores y un grueso de críticos han interpretado su literatura en base de elementos tanto textuales como contextuales que limitaban el alcance de esa revuelta: contenido (simplificado), posicionamiento ideológico (autorial y narratorial), ubicación geográfica, o trasfondo histórico. Dichas limitaciones acotaban el perfil y los significados de los relatos, convirtiéndolos a veces en lemas de unas directrices ideológicas que respetaban al pie de la letra el combate a favor de una lengua y su comunidad. En definitiva, la conclusión de dicha interpretación llevaba a catalogarlo como uno más del sector que, por la vía tradicional, pretendía mostrar ese compromiso grave y sincero, sin medias tintas, ni mucho menos embrollos conceptuales. Tal fue el misreading que Gregori Soldevila quiso denunciar — entre otras cosasal aproximarse a la narrativa de Moncada desde unos sólidos planteamientos teóricos. Ahora bien, intentar erradicar de la interpretación de sus relatos la materia ideológica ligada a la historia y la memoria que todo el entramado narrativo presenta — reducirlo a una cuestión "puramente marginal", como hace Alonso (1997, p. 75) - resulta igual de contraproducente, puesto que coarta ciertas obviedades (con)textuales y el sentido común que creemos poseer muchos lectores.

\section{AGRADECIMIENTOS}

Quisiera dedicar el presente estudio a Maila Lema, con el corazón y la razón siempre en el lugar debido. 


\section{BIBLIOGRAFÍA}

Alonso, V. (1997). "Jesús Moncada o l'art de contar amb la mà esquerra". Caplletra, 22, 69-80. doi:10.7203/caplletra.22.7318

Cònsul, I. (1995). Llegir i escriure: Papers de crítica literària. Els Orígens, 37. Barcelona: La Magrana.

- (2005). "No badi, cregui'm, això dura poc: La mort en els contes de Jesús Moncada". Serra d'Or, $550,44-46$.

Crameri, K. (2003). "Forging the community: Explorations of memory in two novels by Jesús Moncada". The Modern Language Review, 98 (2), 353-366. doi:10.2307/3737816

- (2011). "Introduction". En K. Crameri (Ed.), Where the Rivers Meet: Jesús Moncada (pp. 9-21). Anglo-Catalan Society Occasional Papers. Nottingham: Five Leaves Publications \& Anglo-Catalan Society.

Cuesta, J. (2008). La odisea de la memoria: Historia de la memoria en España. Siglo XX. Madrid: Alianza.

Gregori, A. (2015). La dimensión política de lo irreal: El componente ideológico en la narrativa fantástica española y catalana. Filologia Romańska, 56. Poznań: Wydawnictwo Naukowe UAM.

- (2016). "A head game or a debate about saints? Fantasy and references to republican ideology and policy in Jesús Moncada's short stories". En E. Samper (Ed.), The Myths of the Republic: Literature and Identity (pp. 223-236). Estudis Catalans, 8. Kassel: Reichenberger.

Gregori Soldevila, C. (2006). "Metaficció irònica a Estremida memòria de Jesús Moncada". Caplletra, 41, 131-150. doi:10.7203/caplletra.41.4833

Martínez-Gil, V. (2006). "Els escriptors com a intel·lectuals postmoderns". En R. Panyella \& J. Marrugat (Eds.), L'escriptor i la seva imatge: Contribució a la història dels intel-lectuals en la literatura catalana contemporània (pp. 299-322). Barcelona: GELCC \& Avenç.

Moncada, J. (2001). Contes. Barcelona: La Magrana.

Nemes, K. (2013). "Mort a Mequinensa". En Actes del Simposi Internacional "Catalanistica a Hongria (1971/72-2011/12)", Budapest, 24-26 abril 2012 (pp. 149-156). Budapest: Eötvös Loránd Tudományegyetem.

Parcerisas, F. (2005). "La creació del món”. Serra d’Or, 550, 37-39.

Ribes, S. (2004). "L'evolució de la sàtira de la dictadura a l'obra d'en Jesús Moncada". En C. Camps \& P. Arnau (Eds.), Col-loqui europeu d'estudis catalans, II: La literatura catalana de la democràcia (pp. 229-240). Montpellier, Centre d'études et de recherches catalanes Université Montpellier III \& Association Française des Catalanistes.

- (2011). "The short stories: the universe and voices of Mequinensa". En K. Crameri (Ed.), Where the Rivers Meet: Jesús Moncada (pp. 56-93). Anglo-Catalan Society Occasional Papers. Nottingham: Five Leaves Publications \& Anglo-Catalan Society.

Traverso, E. (2006). Els usos del passat: Història, memòria, política (trad. G. Muñoz). Assaig, 16. Valencia: Universitat de València. 